\title{
Biomarkers and clinical scores to identify patient populations at risk of delayed antibiotic administration or intensive care admission
}

Juan Gonzalez del Castillo ${ }^{1,2}$ [D, Darius Cameron Wilson ${ }^{3 *}$, Carlota Clemente-Callejo ${ }^{1}$, Francisco Román ${ }^{4}$, Ignasi Bardés-Robles ${ }^{5}$, Inmaculada Jiménez ${ }^{4}$, Eva Orviz ${ }^{6}$, Macarena Dastis-Arias $^{7}$, Begoña Espinosa ${ }^{4}$, Fernando Tornero-Romero ${ }^{6}$, Jordi Giol-Amich ${ }^{5}$, Veronica González ${ }^{4}$, Ferran Llopis-Roca ${ }^{5}$ on behalf of the INFURG-SEMES investigators

\begin{abstract}
Background: The performance of blood biomarkers (mid-regional proadrenomedullin (MR-proADM), procalcitonin (PCT), C-reactive protein (CRP), and lactate) and clinical scores (Sequential Organ Failure Assessment (SOFA), National Early Warning Score (NEWS), and quick SOFA) was compared to identify patient populations at risk of delayed treatment initiation and disease progression after presenting to the emergency department (ED) with a suspected infection.

Methods: A prospective observational study across three EDs. Biomarker and clinical score values were calculated upon presentation and $72 \mathrm{~h}$, and logistic and Cox regression used to assess the strength of association. Primary outcomes comprised of 28-day mortality prediction and delayed antibiotic administration or intensive care (ICU) admission, whilst secondary outcomes identified subsequent disease progression.
\end{abstract}

Results: Six hundred eighty-four patients were enrolled with hospitalisation, ICU admission, and infection-related 28-day mortality rates of $72.8 \%, 3.4 \%$, and $4.4 \%$, respectively. MR-proADM and NEWS had the strongest association with hospitalisation and the requirement for antibiotic administration, whereas MR-proADM alone had the strongest association with ICU admission (OR [95\% Cl]: 5.8 [3.1 - 10.8]) and mortality (HR [95\% Cl]: 3.8 [2.2 - 6.5]). Patient subgroups with high MR-proADM concentrations ( $\geq 1.77 \mathrm{nmol} / \mathrm{L}$ ) and low NEWS ( $<5$ points) values had significantly higher rates of ICU admission (8.1\% vs 1.6\%; $p<0.001$ ), hospital readmission (18.9\% vs. $5.9 \% ; p<0.001)$, infection-related mortality $(13.5 \%$ vs. $0.2 \% ; p<0.001)$, and disease progression $(29.7 \%$ vs. $4.9 \% ; p<0.001)$ than corresponding patients with low MR-proADM concentrations. ICU admission was delayed by 1.5 [0.25 - 5.0] days in patients with high MR-proADM and low NEWS values compared to corresponding patients with high NEWS values, despite similar 28 -day mortality rates (13.5\% vs. 16.5\%). Antibiotics were witheld in $17.4 \%$ of patients with high MR-proADM and low NEWS values, with higher subsequent rates of ICU admission (27.3\% vs. 4.8\%) and infection-related hospital readmission (54.5\% vs. 14.3\%) compared to those administered antibiotics during ED treatment.

Conclusions: Patients with low severity signs of infection but high MR-proADM concentrations had an increased likelihood of subsequent disease progression, delayed antibiotic administration or ICU admission. Appropriate triage decisions and the rapid use of antibiotics in patients with high MR-proADM concentrations may constitute initial steps in escalating or intensifying early treatment strategies.

Keywords: MR-proADM, Infection, Sepsis, NEWS, qSOFA, Disease progression, Emergency department, Intensive care unit

\footnotetext{
*Correspondence: Dwilso52@caledonian.ac.uk

${ }^{3}$ Shock, Organ Dysfunction and Resuscitation Research Group, Vall d'Hebron

Institute of Research, Barcelona, Spain

Full list of author information is available at the end of the article
}

(c) The Author(s). 2019 Open Access This article is distributed under the terms of the Creative Commons Attribution 4.0 International License (http://creativecommons.org/licenses/by/4.0/), which permits unrestricted use, distribution, and reproduction in any medium, provided you give appropriate credit to the original author(s) and the source, provide a link to the Creative Commons license, and indicate if changes were made. The Creative Commons Public Domain Dedication waiver (http://creativecommons.org/publicdomain/zero/1.0/) applies to the data made available in this article, unless otherwise stated. 


\section{Background}

Delayed treatment in patients presenting to the emergency department (ED) with a suspected infection may result in a prolonged hospitalisation, an increased morbidity, and a greater rate of infection-related mortality [1-3]. An accurate assessment of the severity of the host response and the potential for further disease progression and organ dysfunction is therefore crucial in order to administer a rapid and targeted therapeutic response.

The lack of validated tools to help guide therapeutic decision-making in patients presenting with low severity National Early Warning Score (NEWS) or quick Sequential Organ Failure Assessment (qSOFA) values, but with a high subsequent likelihood of further disease progression, is therefore of significant concern $[4,5]$. Antibiotics are often administered before any final clinical diagnosis can be made [6], resulting in an increased likelihood of inappropriate therapy, growing levels of antibiotic resistance, and detrimental effects on the microbiota. Conversely, delayed treatment in high severity patients may lead to increased morbidity and mortality rates [7]. In addition, an early and inappropriate discharge from the ED may also result in higher mortality rates in patients later rehospitalised and directly admitted onto an intensive care unit (ICU), with similar findings also reported after an inappropriate initial admission onto a medical ward [8]. Thus, difficulties in identifying infectionrelated disease severity and the early pathophysiological changes involved in a deteriorating host response may contribute to poor overall decision-making and higher subsequent rates of hospital readmission [8-10].

Despite the presence of a number of independent risk factors [11-13], few studies have identified patient subgroups at risk of delayed antibiotic therapy or ICU triage, and the subsequent likelihood of further disease progression. It is therefore unsurprising that no validated test has been incorporated into routine clinical use. A recent investigation, however, found that the blood biomarker, mid-regional proadrenomedullin (MR-proADM), could accurately identify patients with non-severe clinical signs of infection but a high likelihood of further disease progression [4]. Indeed, recent studies have shown MRproADM to improve National Early Warning Score (NEWS) performance in an undifferentiated ED population with mild clinical symptoms [14], identify disease progression in sepsis patients with decreasing procalcitonin (PCT) concentrations [15], and accurately identify non-surviving patients with low levels of organ dysfunction who later developed multiple organ failure [16].

This study therefore aimed to assess the potential use of MR-proADM in identifying high severity patient subgroups at risk of a delayed or insufficient initial treatment, identified by a decision to (i) withhold or delay antibiotic administration, or (ii) delay ICU admission.
Biomarker kinetics between ED presentation and $72 \mathrm{~h}$ within patient subgroups were further investigated to identify subsequent cases of disease progression and mortality.

\section{Methods \\ Study design and ethical approval}

This prospective study consecutively enrolled patients presenting with a suspected infection to the EDs of three large tertiary level university hospitals (> 800 beds), comprising of the Hospital Clínico Universitario San Carlos (Madrid), the Hospital Universitari de Bellvitge (Barcelona), and the Hospital General Universitario de Alicante (Alicante). All patients were enrolled in accordance with the Helsinki Declaration, and ethical approval granted from the relevant governance bodies. The study was registered on ClinicalTrials.gov with the identifier NCT03992794.

\section{Inclusion and exclusion criteria}

Inclusion criteria comprised of patients $\geq 18$ years of age presenting with a clinical suspicion of infection as judged by the treating physician based on usual clinical practice, and could be made according to vital signs, main presenting symptoms, the request for a blood culture, or overall laboratory findings during standard ED assessment. Local study coordinators were responsible for collecting and recording all clinical data on a standardised case report form for each patient throughout the investigation. Exclusion criteria comprised of patients $<18$ years of age, pregnancy, a refusal to participate, and no obvious clinical signs or symptoms of infection.

\section{Data collection and biomarker measurements}

Patient demographics, comorbidities, initial diagnoses, and results from routine laboratory and microbiology tests were either recorded upon study enrolment or retrospectively added. CRP and lactate measurements were measured as part of the standard routine assessment, with a second blood draw taken from each patient during the initial clinical assessment to measure PCT and MR-proADM concentrations using a non-commercially available pointof-care duplex biomarker device (Samsung LABGEO IB10, Nexus, USA). The location of each patient after $72 \mathrm{~h}$ was further identified, with both clinical data and an additional blood sample for PCT and MR-proADM measurement taken in patients still hospitalised at this time point. Samples were measured within 15 min of being drawn by the study coordinator at each site; thus, neither PCT nor MR-proADM results were made available to the treating physician throughout patient enrolment or hospitalisation. Survival and ICU admission time was censored at 28 days following ED presentation, and patients discharged prior to this time point were subsequently contacted by phone to ascertain survival status. 


\section{Study endpoints}

Study endpoints were defined as follows: antibiotic administration - administration of intravenous, oral, or intramuscular antibiotics during ED treatment; length of time to antibiotic administration - length of time from arrival in the ED to the first administration of antibiotics; delayed antibiotic administration - initiation of antibiotic therapy $\geq 180$ min following arrival in the ED [17, 18]; hospitalisation - hospital admission with a subsequent stay of $>24 \mathrm{~h}$; intensive care unit (ICU) admission - all-cause ICU admission within 28 days of study enrolment which could be further categorised into three categories: immediate ( 0 days same day as ED presentation), delayed (between 1 and 7 days following ED presentation), and late ( $>7$ days following presentation); hospital readmission - readmission due to an infection-related symptom or cause within 28 days following ED or hospital discharge; 28-day mortality mortality within 28 days due to an infection-related cause; and disease progression - composite endpoint consisting of infection-related 28-day mortality, ICU admission, and a $\geq$ 2 point increase in NEWS or SOFA score between presentation and $72 \mathrm{~h}$.

\section{Primary and secondary outcomes}

Primary study outcomes comprised of 28-day mortality prediction and the identification of patient populations enriched for a delayed (i) antibiotic administration, or (ii) ICU admission. Secondary outcomes comprised of patient populations enriched according to (iii) subsequent disease progression.

\section{Statistical analysis}

Symmetrically distributed data were reported using mean and standard deviation values, whilst skewed data reported using median, first quarter, and third quarter values. Demographic and clinical data were assessed using the chi-square $\left(\chi^{2}\right)$ for categorical variables, and either Student's $t$ test or the Mann-Whitney $U$ test for symmetrical or skewed continuous variables, respectively. Receiver operating characteristic (ROC) and areas under the curve (AUC) determined the predictive value of each parameter for 28-day mortality, antibiotic administration, hospitalisation, and ICU admission decisions, with 95\% confidence intervals $(95 \% \mathrm{CI})$ used to determine significance. Optimised cut-off values for sensitivity and specificity were determined using Youden's criterion, and patient subgroups subsequently identified according to optimised cut-off values for the prediction of 28-day mortality, similar to methods outlined by Saeed et al. [4]. Kaplan-Meier curves categorised patients on ED presentation according to either optimised or pre-established 28-day mortality cutoffs for all biomarkers and scores, with the most accurate parameter used to further stratify subgroups. Treatment and outcome characteristics of each resulting subgroup, comprising of antibiotic, hospitalisation, disease progression, intensive care, and mortality-related variables, were compared using the log-rank test for mortality; the chisquare $\left(x^{2}\right)$ test for disease progression, hospitalisation, ICU admission, and antibiotic administration; and the Mann-Whitney U test for the overall length of hospitalisation. Univariate and multivariate Cox regression analyses assessed the association of each parameter with time to mortality, whilst corresponding logistic regression assessed the association with antibiotic administration, hospitalisation, and ICU admission decisions. Potential confounding variables were selected based on a univariate survival analysis for infection-related 28-day mortality and subsequently included in all further multivariate analyses as adjusting variables. Results were presented as either the hazard (HR) or the odds (OR) ratio per 1 interquartilerange increase for Cox and logistic regression analyses, respectively. A $p$ value $<0.05$ was considered statistically significant, and all data analysed using the statistics software $\mathrm{R}$ (version 3.1.2). Due to the exploratory nature of the primary and secondary endpoints, no a priori sample size calculation could be performed.

\section{Results}

\section{Patient characteristics}

A total of 684 patients with suspected infection were consecutively enrolled between May and July 2018 (Fig. 1), with lower respiratory tract and urogenital infections the most common origins of infection (Table 1; Additional file 1: Table S1). Only $55.6 \%(N=380)$ of patients remained hospitalised after $72 \mathrm{~h}$ following ED presentation (Additional file 1: Table S2).

\section{Treatment decisions within the total population}

Antibiotics were administered to $73.8 \%(N=505)$ of patients during treatment within the ED, with $15.2 \%(N=$ 104) already undergoing therapy prior to presentation. The median time from presentation to administration was $186(120-330) \mathrm{min}$, with the decision to hospitalise concurrently made in $72.8 \%(N=498)$ of patients (Table 1). ICU admission was required in $3.4 \%(N=23)$ of patients, with $47.8 \%(N=11)$ of admissions occurring on the same day as ED presentation. The overall median time to admission was $1(0-11.5)$ day. Univariate logistic regression found that NEWS and MR-proADM had the strongest association with antibiotic administration (NEWS vs. MR-proADM OR [95\% CI] 5.5 [3.6 - 8.2] vs. 4.9 [3.5 - 6.8]; Additional file 1: Table S3) and hospitalisation (NEWS vs. MR-proADM OR [95\% CI] 6.0 [4.0 - 9.1] vs. 6.6 [4.6 - 9.4]; Additional file 1: Table S5) decisions, whereas MR-proADM alone had the highest association with the requirement for ICU admission (OR [95\% CI] 4.1 [2.3 - 7.1]; Additional file 1: Table S7). Multivariate analysis was adjusted by age, diabetes, malignancy, and 


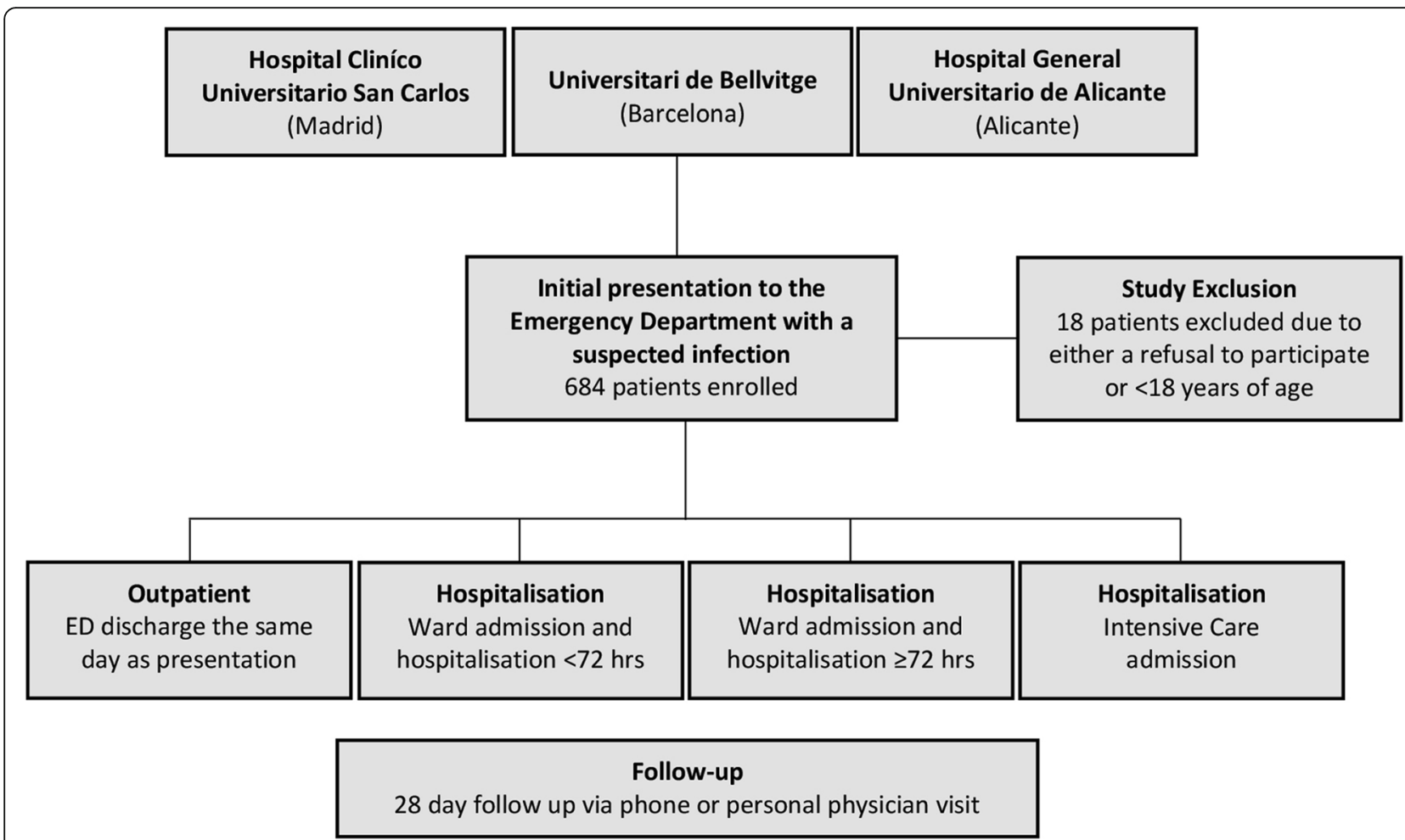

Fig. 1 Patient enrolment and follow-up process

liver and renal disease variables, with the association for NEWS and MR-proADM maintained for each endpoint (Fig. 2; Additional file 1: Tables S3, S5, and S7). Addition of MR-proADM to each of the other biomarkers and scores significantly improved association for each endpoint (Additional file 1: Tables S4, S6, and S8). Corresponding AUROC analysis found similar results, with MR-proADM having the greatest accuracy and the highest diagnostic odds ratio for each endpoint (Additional file 1: Figures S1-S3).

\section{Subgroup enrichment for infection-related mortality upon} ED presentation and $72 \mathrm{~h}$

The infection-related 28-day mortality rate upon presentation and $72 \mathrm{~h}$ was $4.4 \%(N=30$; Table 1$)$ and $6.8 \%$ $(N=26$; Additional file 1: Table S2), respectively. Nonsurvivors were significantly older and had a median time to mortality of $11(4.25-19.50)$ days, with the most common cause of death being either single or multiple organ failure $(N=22 ; 73.3 \%)$. Non-infected related mortalities $(N=4)$ comprised of cerebral haemorrhage and issues relating to a prior trauma. All biomarkers and clinical scores were significantly increased in the nonsurviving population, with the exception of CRP (Table 1). Univariate (Additional file 1: Tables S9 and S11) and multivariate (Table 2) Cox regression found that MR-proADM had the greatest association with mortality upon presentation and $72 \mathrm{~h}$, although the strength of association decreased between both time points. Addition of MR-proADM to each of the other biomarkers and scores significantly improved association at both time points (Additional file 1: S10 and S12). Corresponding AUROC analysis found similar results (Additional file 1: Figure S4), with an MRproADM cut-off of $1.77 \mathrm{nmol} / \mathrm{L}$ at presentation resulting in the highest prognostic odds ratio. KaplanMeier curve analysis found that MR-proADM could most accurately identify low and high disease severity populations compared to other biomarkers or scores upon presentation (Fig. 3; Additional file 1: Tables S13 and S14) and after $72 \mathrm{~h}$ (Additional file 1: Tables S15 and 16).

In patients with low NEWS values $(<5$ points, $N=$ 499), MR-proADM was found to have the greatest performance of all biomarkers in predicting 28-day mortality $(N=10 ; 2.0 \%$; AUROC [95\% CI] 0.95 [0.92 - 0.98]), followed by PCT and lactate (AUROC $[95 \% \mathrm{CI}] 0.78$ $[0.70-0.86]$ and $0.72[0.56-0.87]$, respectively). The presence of low NEWS and high MR-proADM $(\geq 1.77$ $\mathrm{nmol} / \mathrm{L}$ ) values on ED presentation resulted in a patient subgroup $(N=75 ; 11.3 \%)$ enriched for cases of infectionrelated mortality (Fig. 4C), with similar subgroups (e.g. low lactate, qSOFA, and CRB-65) found for other biomarkers and clinical scores (Fig. 4). 
Table 1 Patient characteristics in the total population and with regard to infection-related 28-day mortality

\begin{tabular}{|c|c|c|c|c|}
\hline Patient characteristics & Total cohort $(N=684)$ & Survivors $(N=654)$ & Non-survivors $(N=30)$ & $p$ value \\
\hline \multicolumn{5}{|l|}{ Demographics } \\
\hline Age (years) & $65.1(19.6)$ & $64.4(19.8)$ & $78.9(9.0)$ & $<0.001$ \\
\hline Male sex $(N, \%)$ & $366(53.5 \%)$ & $352(53.8 \%)$ & $14(46.7 \%)$ & 0.442 \\
\hline \multicolumn{5}{|l|}{ Disposition } \\
\hline Hospital admission $(N, \%)$ & 498 (72.8\%) & 469 (71.7\%) & $29(96.7 \%)$ & 0.003 \\
\hline Hospital length of stay (days) & $3[0-7.25]$ & $3[0-7]$ & $12[3-20.5]$ & $<0.001$ \\
\hline ICU admission $(N, \%)$ & $23(3.4 \%)$ & $19(2.9 \%)$ & $4(13.3 \%)$ & 0.002 \\
\hline \multicolumn{5}{|l|}{ Comorbidities } \\
\hline Cardiovascular disease $(N, \%)$ & $255(37.3 \%)$ & $239(36.5 \%)$ & $16(53.3 \%)$ & 0.063 \\
\hline Diabetes $(N, \%)$ & $152(22.2 \%)$ & $140(21.4 \%)$ & $12(40.0 \%)$ & 0.017 \\
\hline Immunodeficiency $(N, \%)$ & $105(15.4 \%)$ & $97(14.8 \%)$ & $8(26.7 \%)$ & 0.079 \\
\hline Liver disease $(N, \%)$ & $54(7.9 \%)$ & $48(7.3 \%)$ & $6(20.0 \%)$ & 0.012 \\
\hline Malignancy ( $N, \%)$ & $183(26.8 \%)$ & $169(25.8 \%)$ & $14(46.7 \%)$ & 0.012 \\
\hline Neurological disorders (N, \%) & $132(19.3 \%)$ & $125(19.1 \%)$ & 7 (23.3\%) & 0.567 \\
\hline Respiratory disease $(N, \%)$ & $180(26.3 \%)$ & $173(26.5 \%)$ & $7(23.3 \%)$ & 0.704 \\
\hline Renal disease $(N, \%)$ & $128(18.7 \%)$ & $117(17.9 \%)$ & $11(36.7 \%)$ & 0.010 \\
\hline \multicolumn{5}{|l|}{ Infectious source } \\
\hline Bone and joint $(N, \%)$ & $4(0.6 \%)$ & $3(0.5 \%)$ & $1(3.3 \%)$ & 0.044 \\
\hline Cardiac (N, \%) & $2(0.3 \%)$ & $1(0.2 \%)$ & $1(3.3 \%)$ & 0.002 \\
\hline Intra-abdominal (N, \%) & $93(13.6 \%)$ & $86(13.1 \%)$ & $7(23.3 \%)$ & 0.112 \\
\hline Respiratory — lower (N, \%) & $220(32.2 \%)$ & 206 (31.5\%) & $14(46.7 \%)$ & 0.082 \\
\hline Respiratory — upper (N, \%) & $18(2.6 \%)$ & $18(2.8 \%)$ & $0(0.0 \%)$ & 0.357 \\
\hline Skin and soft tissue $(N, \%)$ & $36(5.3 \%)$ & $35(5.4 \%)$ & $1(3.3 \%)$ & 0.628 \\
\hline Surgical related $(N, \%)$ & $16(2.3 \%)$ & $16(2.4 \%)$ & $0(0.0 \%)$ & 0.386 \\
\hline Unknown origin $(N, \%)$ & $81(11.8 \%)$ & $80(12.2 \%)$ & $1(3.3 \%)$ & 0.140 \\
\hline Urogenital $(N, \%)$ & $214(31.3 \%)$ & $209(32.0 \%)$ & $5(16.7 \%)$ & 0.077 \\
\hline \multicolumn{5}{|l|}{ Blood cultures } \\
\hline Blood cultures taken $(N, \%)$ & $407(59.5 \%)$ & $390(59.6 \%)$ & $17(56.7 \%)$ & 0.746 \\
\hline Positive blood cultures ( $N, \%)$ & $58(14.3 \%)$ & $55(8.4 \%)$ & $3(10.0 \%)$ & 0.756 \\
\hline Gram-positive bacteria $(N, \%)$ & $15(2.2 \%)$ & $14(2.1 \%)$ & $1(3.3 \%)$ & 0.326 \\
\hline Gram-negative bacteria $(N, \%)$ & $35(5.1 \%)$ & $33(5.0 \%)$ & $2(6.7 \%)$ & 0.762 \\
\hline Gram-positive and gram-negative bacteria $(N, \%)$ & $8(1.2 \%)$ & $7(1.1 \%)$ & $1(3.3 \%)$ & 0.737 \\
\hline \multicolumn{5}{|l|}{ Biomarkers and severity scores } \\
\hline MR-proADM (nmol/L) & $1.09[0.70-1.71]$ & $1.05[0.68-1.64]$ & $2.32[1.89-2.96]$ & $<0.001$ \\
\hline $\mathrm{PCT}(\mathrm{ng} / \mathrm{mL})$ & $0.21[0.10-0.98]$ & $0.2[0.10-0.90]$ & $0.59[0.21-3.78]$ & $<0.001$ \\
\hline Lactate $(\mathrm{mmol} / \mathrm{L})$ & $1.5[1.1-2.1]$ & $1.5[1.1-2.1]$ & $2.1[1.58-2.83]$ & $<0.01$ \\
\hline CRP (mg/L) & $10.52[3.17-26.3]$ & $10.52[3.12-25.63]$ & $9.99[6.36-18.35]$ & 0.925 \\
\hline SOFA (points) & $1[0-3]$ & $1[0-3]$ & $4[3-5]$ & $<0.001$ \\
\hline qSOFA (points) & $0[0-1]$ & $0[0-1]$ & $1[1-1]$ & $<0.05$ \\
\hline SIRS (points) & $1[1-2]$ & $1[1-2]$ & $2[1-2]$ & $<0.001$ \\
\hline NEWS (points) & $2[1-5]$ & $2[1-5]$ & $6[3.25-7.75]$ & $<0.001$ \\
\hline CRB-65 (points) & $1[0-2]$ & $1[0-1]$ & $2[1-2]$ & $<0.001$ \\
\hline
\end{tabular}

Values expressed in percentages (\%) indicate the proportion of patients within each cohort for each variable. Data are presented as mean (standard deviation, SD) or median [first quartile (Q1)-third quartile (Q3)] where specified. The chi-square $\left(x^{2}\right)$ test was used to determine significance between the cohorts for categorical variables, Student's $t$ test for the variable of age, and Mann-Whitney $U$ test for hospitalisation duration, biomarker, and clinical score variables. CRB-65 severity score for community-acquired pneumonia, CRP C-reactive protein, ICU intensive care unit, MR-proADM midregional proadrenomedullin, N number, NEWS National Early Warning Score, PCT procalcitonin, qSOFA quick Sequential Organ Failure Assessment, SIRS systemic inflammatory response syndrome, SOFA Sequential Organ Failure Assessment 

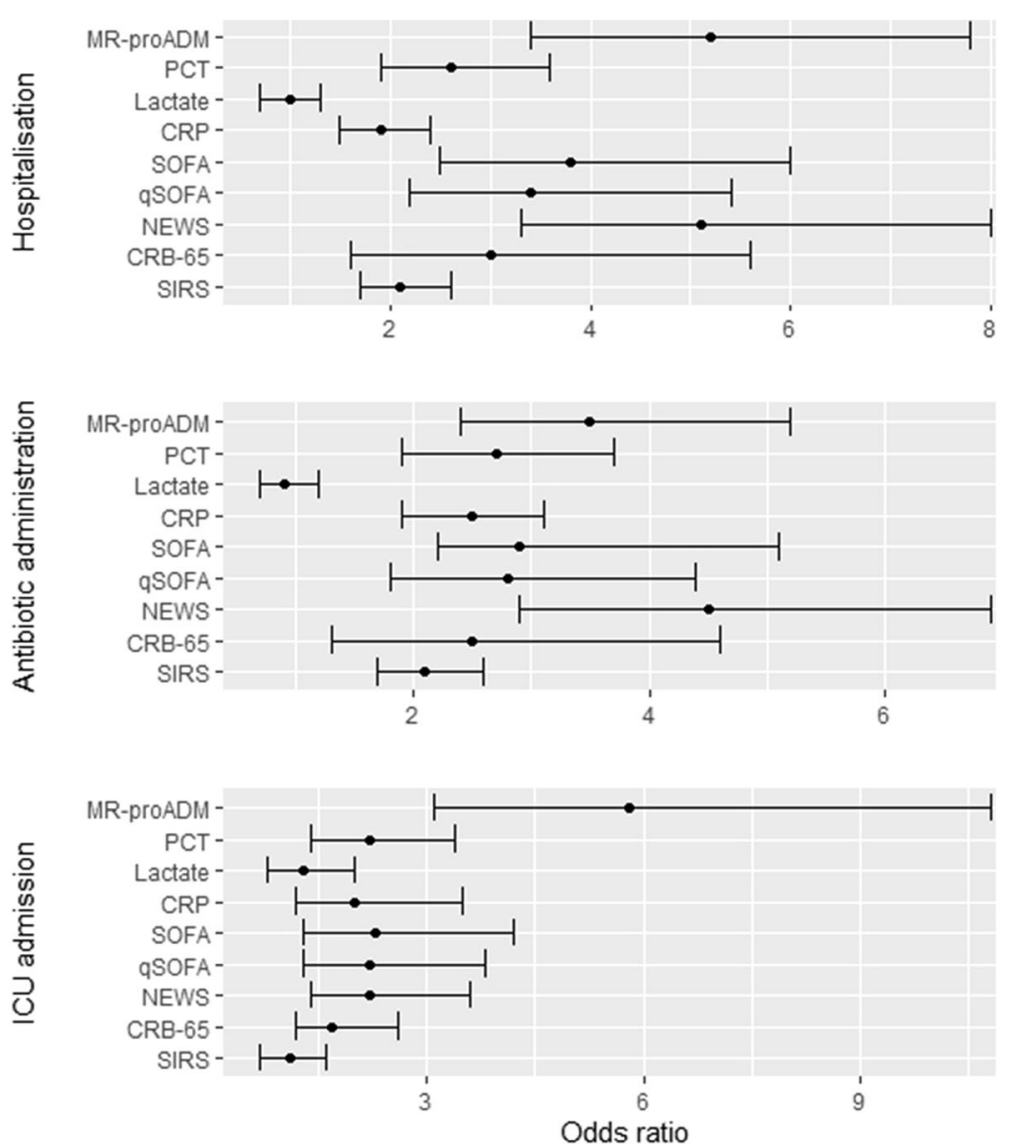

Fig. 2 Multivariate logistic regression for all biomarkers and clinical scores for antibiotic administration, hospitalisation, and intensive care (ICU) admission endpoints. CRB-65, severity score for community-acquired pneumonia; CRP, C-reactive protein; MR-proADM, mid-regional proadrenomedullin; NEWS, National Early Warning Score; PCT, procalcitonin; SIRS, systemic inflammatory response syndrome; qSOFA, quick Sequential Organ Failure Assessment; SOFA, Sequential Organ Failure Assessment

\section{Subgroup enrichment for withheld or delayed antibiotic therapy}

The proportion of patients receiving antibiotics $<180$ mins after ED arrival was significantly $(p<0.01)$ lower in the high MR-proADM and low lactate $(N=32 ; 45.7 \%)$ as opposed to the high MR-proADM and high lactate $(N=$ 38 ; 66.7\%) subgroup, despite similar rates of infectionrelated readmission and mortality, ICU admission, and disease progression (Additional file 1: Table S17). Comparable results could also be found for MR-proADM and qSOFA subgroups (Additional file 1: Table S18), whereas no such trend could be found for MR-proADM and either NEWS (Table 3) or CRB-65 (Additional file 1: Table S19).

Nevertheless, patients with low NEWS and low MRproADM values could be further categorised according to whether antibiotics were administered or withheld during ED treatment, with no significant differences found in subsequent ICU admission, hospital readmission, or infection-related mortality rates irrespective of antibiotic administration (Additional file 1: Table S20). Conversely, antibiotic administration in the low NEWS and high MR-proADM subgroup resulted in significantly lower ICU admission $(N=3,4.8 \%$ vs. $N=3,27.3 \%$; $p<$ $0.001)$ and hospital readmission rates $(N=9,14.3 \%$ vs. $N=6,54.5 \% ; p<0.001)$ compared to corresponding patients where therapy was withheld (Additional file 1: Table S20). Similar results were also observed for MRproADM and qSOFA subgroups depending on antibiotic administration (Additional file 1: Table S21).

\section{Subgroup enrichment for delayed ICU admission}

Patients with low NEWS and high MR-proADM values had a significantly higher risk of overall as well as delayed ICU admission compared to corresponding patients with low MR-proADM concentrations $(p<0.001)$, with an average time to admission of 1.5 [0.25 - 5] days (Table 3 ). This comprised of 2 patients initially deemed suitable for outpatient treatment, but later directly admitted onto the ICU after re-presenting to the ED, as well as 4 patients initially triaged onto a medical ward before subsequent ICU admission. Conversely, no significant differences in admission rate were found compared to the high NEWS and 
Table 2 Multivariate Cox regression analysis for the prediction of 28-day mortality upon ED presentation and after $72 \mathrm{~h}$ of hospitalisation

\begin{tabular}{|c|c|c|c|c|c|}
\hline Biomarker or clinical score & Patients $(N)$ & Number of events $(M)$ & $\operatorname{LR} x^{2}$ & $p$ value & $\mathrm{HR}[95 \% \mathrm{Cl}]$ \\
\hline \multicolumn{6}{|c|}{ 28-day mortality prediction upon ED presentation } \\
\hline MR-proADM & 684 & 30 & 53.1 & $<0.001$ & $3.8[2.2-6.5]$ \\
\hline PCT & 684 & 30 & 38.2 & $<0.001$ & $1.7[1.1-2.5]$ \\
\hline Lactate & 533 & 30 & 34.8 & $<0.001$ & $1.5[1.1-2.1]$ \\
\hline CRP & 646 & 28 & 29.0 & $<0.001$ & $0.9[0.6-1.4]$ \\
\hline SOFA & 684 & 30 & 53.7 & $<0.001$ & $3.2[2.1-5.0]$ \\
\hline qSOFA & 684 & 30 & 46.5 & $<0.001$ & $2.3[1.6-3.5]$ \\
\hline NEWS & 684 & 30 & 42.2 & $<0.001$ & $2.0[1.3-2.9]$ \\
\hline CRB-65 & 684 & 30 & 39.8 & $<0.001$ & $1.5[1.1-2.0]$ \\
\hline SIRS & 684 & 30 & 35.4 & $<0.001$ & $1.4[1.0-1.9]$ \\
\hline \multicolumn{6}{|c|}{ 28-day mortality prediction after $72 \mathrm{~h}$ of hospitalisation } \\
\hline MR-proADM & 375 & 25 & 36.6 & $<0.001$ & $3.0[1.8-4.9]$ \\
\hline PCT & 370 & 25 & 26.2 & $<0.001$ & $1.6[1.1-2.4]$ \\
\hline Lactate & 266 & 24 & 20.1 & $<0.01$ & $1.0[0.7-1.5]$ \\
\hline CRP & 281 & 20 & 17.6 & $<0.001$ & $0.8[0.4-1.3]$ \\
\hline SOFA & 375 & 25 & 33.7 & $<0.001$ & $2.0[1.4-2.7]$ \\
\hline qSOFA & 376 & 25 & 22.5 & $<0.001$ & $1.4[0.8-2.3]$ \\
\hline NEWS & 376 & 25 & 26.5 & $<0.001$ & $1.6[1.1-2.3]$ \\
\hline CRB-65 & 376 & 25 & 22.3 & $<0.001$ & $1.3[0.8-2.2]$ \\
\hline SIRS & 376 & 25 & 24.9 & $<0.001$ & $1.5[1.0-2.3]$ \\
\hline
\end{tabular}

Multivariate analysis was adjusted by age, diabetes, malignancy, and liver and renal disease variables. $C l$ confidence interval, $C R B-65$ severity score for communityacquired pneumonia, CRP C-reactive protein, $D F$ degrees of freedom, $L R$ likelihood ratio, MR-proADM mid-regional proadrenomedullin, $N$ number, NEWS National Early Warning Score, HR hazard ratio, PCT procalcitonin, qSOFA quick Sequential Organ Failure Assessment, SIRS systemic inflammatory response syndrome, SOFA Sequential Organ Failure Assessment

high MR-proADM subgroup $(N=8 ; 9.4 \%$; Table 3$)$, where all admissions were immediately transferred onto the ICU. Similar findings could also be found for MR-proADM and qSOFA subgroups.

\section{Subgroup enrichment for disease progression and biomarker kinetics to identify non-surviving patients}

Low NEWS and high MR-proADM concentrations on ED presentation resulted in a patient subgroup enriched for cases of subsequent disease progression (Table 3), with similar results also found for combinations of high MR-proADM and low lactate, qSOFA, and CRB-65 (Additional file 1: Tables S17-S19). Interestingly, no significant kinetical differences were found in surviving or non-surviving patients with initially low NEWS values between presentation and $72 \mathrm{~h}$, whilst MR-proADM significantly decreased in survivors $(p<0.001)$ and tended to increase in non-survivors $(p=0.085$; Table 4$)$. Such a kinetical profile was not observed for any other biomarker in patients with initially low NEWS values (Additional file 1: Table S22). Similar subgroup enrichment and comparably increased or continuously elevated kinetics between presentation and $72 \mathrm{~h}$ could also be found in high MR-proADM and low qSOFA (Additional file 1: Table S23), lactate, and CRB-65 subgroups.

\section{Discussion}

The results of this prospective multicentre study confirm those from previous investigations $[4,19]$, highlighting the ability of MR-proADM to identify patients with a high potential for subsequent disease progression [15, 16, 20]. Results also indicate that patients with low presenting symptoms and high MR-proADM concentrations had an increased risk of a less intensive treatment despite high subsequent mortality rates, characterised by a withheld or delayed antibiotic therapeutic response, a delayed admission onto the ICU, and a high readmission rate due to the reoccurrence of an infection-related complication.

Treatment during ED assessment is often initiated before any definitive diagnosis can be made in order to limit the potential for subsequent clinical deterioration [6]. This, however, may be complicated by the heterogeneous and multifaceted host response to infection [21], as well as difficulties in assessing the severity and potential for further disease progression. There is therefore a high likelihood of either an over- or an under-treatment 

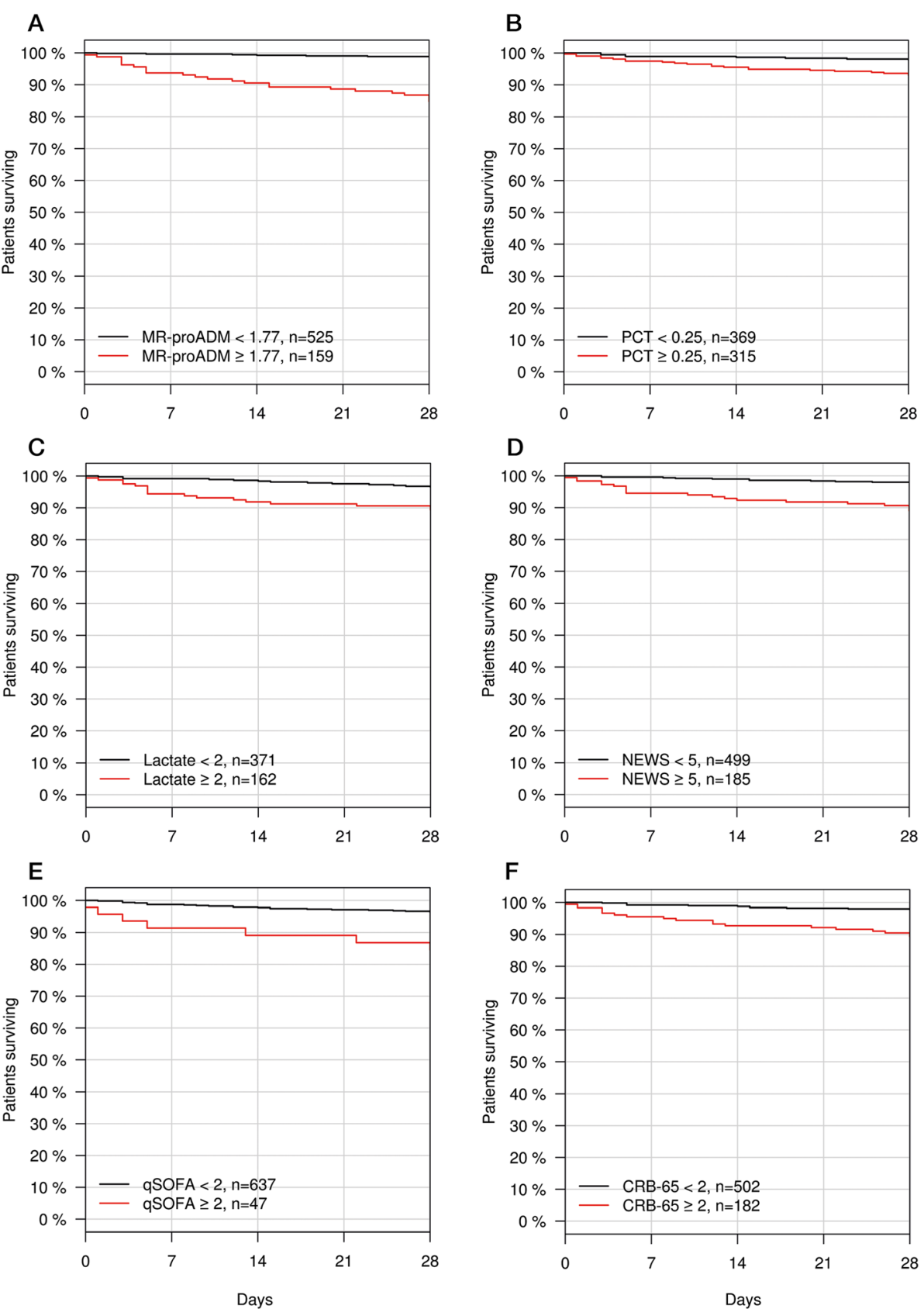

Fig. 3 Kaplan-Meier analysis to identify disease severity subgroups using biomarkers and clinical scores according to MR-proADM (a), PCT (b), lactate (c), NEWS (d), qSOFA (e), and CRB-65 (f) cut-offs. CRB-65, severity score for community-acquired pneumonia; MR-proADM, mid-regional proadrenomedullin; NEWS, National Early Warning Score; qSOFA, quick Sequential Organ Failure Assessment

of patients, both of which are associated with undesirable outcomes. Hence, the use of an easily measurable parameter to accurately assess infection severity and short-term disease progression is highly desirable in order to help guide optimal treatment decision-making. Based on recent evidence, the blood biomarker midregional proadrenomedullin (MR-proADM) may potentially fulfil this unmet clinical need, with elevated concentrations found due to increased capillary leak and deteriorating microcirculatory integrity [22-24]. Such pathophysiological changes, however, are not unique to patients with infection. Indeed, elevated MR-proADM concentrations have been observed across of range of non-infection-related conditions, such as acute and chronic heart failure [25, 26], non-specific complaints [27], and in the build-up to acute episodes of systemic capillary leak syndrome (Clarkson's disease) [28]. Thus, any increase in MR-proADM concentration in patients 

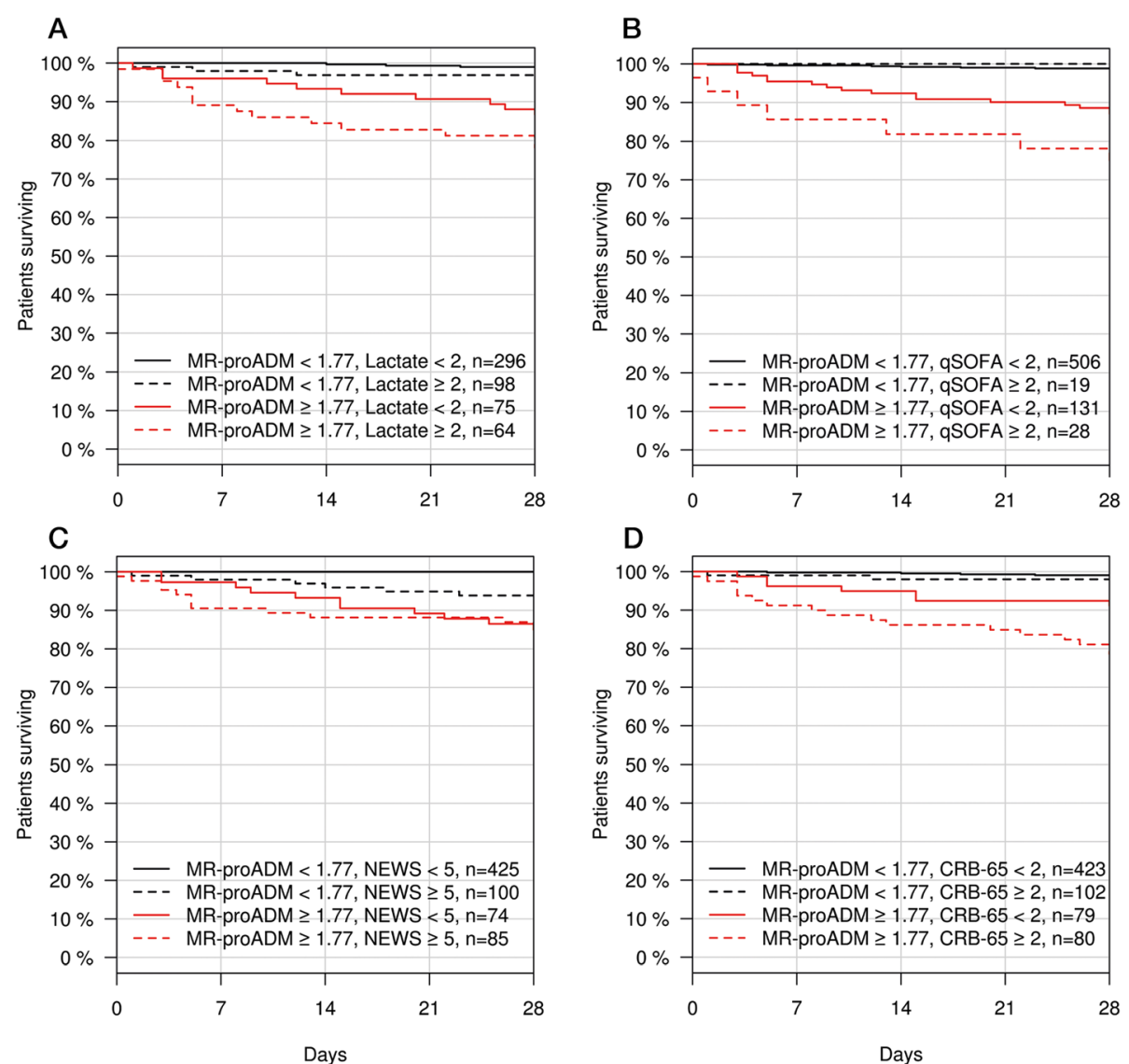

Fig. 4 Kaplan-Meier analysis to identify patient populations enriched for disease progression events. Patients were stratified according to a combination of MR-proADM and lactate (a), qSOFA (b), NEWS (c), and CRB-65 (d). CRB-65, severity score for community-acquired pneumonia; MRproADM, mid-regional proadrenomedullin; NEWS, National Early Warning Score; qSOFA, quick Sequential Organ Failure Assessment

with suspected infection cannot be specifically attributed to the presence of an infectious source, although it may provide an early and accurate prediction of developing organ dysfunction and subsequent mortality [29-34]. Thus, the fundamental challenge in incorporating such a parameter into routine clinical practice therefore relates to the extent to which real life decision-making can either be altered or optimised.

Three potential areas of further observational and interventional research using MR-proADM can therefore be proposed based on the results of this study, as well as current clinical requirements, namely as a potential aid to (i) guide appropriate and timely antibiotic administration, (ii) minimise the risk of inappropriate triage before admission onto an intensive care unit, and (iii) identify treatment failure and disease progression in patients with low severity clinical symptoms.

Firstly, the early administration of oral or intravenous antibiotics in patients presenting with a suspected infection plays a central role in most emergency medicine treatment strategies. However, challenges concerning their unnecessary administration are well documented, primarily due to increasing antibiotic resistance and rising healthcare costs. Conversely, the importance of ensuring therapy is rapidly administered to both high severity patients and those with a high potential for further disease progression cannot be overstated [6, 35-38]. As such, no standardised strategy exists to guide antibiotic administration in the ED. Interestingly, our results highlight a greater association with the requirement for antibiotic administration using NEWS and MRproADM, as opposed to more commonly used parameters such as CRP and PCT, which confirm the results of a recent subset analysis [39] from a previous study. This may be in part explained by the rapid kinetical profile of MR-proADM, which is increased significantly earlier than PCT [40, 41] and many other cytokines [42] in response to microbial infection. Nevertheless, elevated MR-proADM concentrations can also be observed in many non-infectious conditions, albeit to a lesser extent than during a severe infectious episode, making its sole use in guiding antibiotic administration problematic. The combination of PCT and MR-proADM, therefore, may provide an attractive alternative [43-45]. 
Table 3 Patient subgroups stratified by NEWS and MR-proADM

\begin{tabular}{|c|c|c|c|c|c|c|c|c|}
\hline \multirow[t]{3}{*}{ Patient subgroups } & \multicolumn{8}{|c|}{ Patient populations stratified by NEWS and MR-proADM } \\
\hline & $\begin{array}{l}\text { MR-proADM } \\
\text { (nmol/L) }\end{array}$ & $\begin{array}{l}\text { NEWS } \\
\text { (points) }\end{array}$ & $\begin{array}{l}\text { MR-proADM } \\
\text { (nmol/L) }\end{array}$ & $\begin{array}{l}\text { NEWS } \\
\text { (points) }\end{array}$ & $\begin{array}{l}\text { MR-proADM } \\
\text { (nmol/L) }\end{array}$ & $\begin{array}{l}\text { NEWS } \\
\text { (points) }\end{array}$ & $\begin{array}{l}\text { MR-proADM } \\
\text { (nmol/L) }\end{array}$ & $\begin{array}{l}\text { NEWS } \\
\text { (points) }\end{array}$ \\
\hline & $<1.77$ & $<5$ & $\geq 1.77$ & $<5$ & $<1.77$ & $\geq 5$ & $\geq 1.77$ & $\geq 5$ \\
\hline Population, N (\%) & \multicolumn{2}{|l|}{$425(62.1 \%)$} & \multicolumn{2}{|l|}{$74(10.8 \%)$} & \multicolumn{2}{|l|}{$100(14.6 \%)$} & \multicolumn{2}{|l|}{$85(12.8 \%)$} \\
\hline Antibiotic administration, $N(\%)$ & \multicolumn{2}{|l|}{$266(62.6 \%)$} & \multicolumn{2}{|l|}{$63(85.1 \%)$} & \multicolumn{2}{|l|}{$94(94.0 \%)$} & \multicolumn{2}{|l|}{$82(96.5 \%)$} \\
\hline $\begin{array}{l}\text { Time to antibiotic administration } \\
\text { (min) (median [Q1-Q4]) }\end{array}$ & \multicolumn{2}{|l|}{$180[90-342]$} & \multicolumn{2}{|c|}{$205.5[111-300]$} & \multicolumn{2}{|c|}{$210[142-315]$} & \multicolumn{2}{|c|}{$180[100-300]$} \\
\hline Antibiotic administration < $180 \mathrm{~min}, \mathrm{~N}(\%)$ & \multicolumn{2}{|l|}{$108(40.6 \%)$} & \multicolumn{2}{|l|}{$26(41.3 \%)$} & \multicolumn{2}{|l|}{$30(31.9 \%)$} & \multicolumn{2}{|l|}{$33(40.2 \%)$} \\
\hline $\begin{array}{l}\text { i.v. to oral antibiotic change (days) } \\
\text { (median [Q1-Q4]) }\end{array}$ & \multicolumn{2}{|l|}{$1.5[1-4]$} & \multicolumn{2}{|l|}{$4.0[0-6.75]$} & \multicolumn{2}{|l|}{$4[2-6]$} & \multicolumn{2}{|l|}{$3.5[0-4.5]$} \\
\hline Hospitalisation, N (\%) & \multicolumn{2}{|l|}{$260(61.2 \%)$} & \multicolumn{2}{|l|}{$63(85.1 \%)$} & \multicolumn{2}{|l|}{$93(93.0 \%)$} & \multicolumn{2}{|l|}{$82(96.5 \%)$} \\
\hline $\begin{array}{l}\text { Length of hospitalisation (days) (median } \\
\text { [Q1-Q4]) }\end{array}$ & \multicolumn{2}{|l|}{$1[0-5]$} & \multicolumn{2}{|l|}{$6[3-11]$} & \multicolumn{2}{|l|}{$7[4-10]$} & \multicolumn{2}{|l|}{$7[4-13]$} \\
\hline Infection-related readmission, $N(\%)$ & \multicolumn{2}{|l|}{$25(5.9 \%)$} & \multicolumn{2}{|l|}{$14(18.9 \%)$} & \multicolumn{2}{|l|}{$3(3.0 \%)$} & \multicolumn{2}{|l|}{$9(10.6 \%)$} \\
\hline ICU admission, $N(\%)$ & \multicolumn{2}{|l|}{$7(1.6 \%)$} & $6(8.1 \%)$ & & $2(2.0 \%)$ & & $8(9.4 \%)$ & \\
\hline Time to ICU admission (days) (median [Q1-Q4]) & $13[2-20]$ & & $1.5[1-5]$ & & $9.5[4.75-14$. & & $0[0-0]$ & \\
\hline Number of immediate ICU admissions, $N(\%)$ & $0(0.0 \%)$ & & $0(0.0 \%)$ & & $0(0.0 \%)$ & & $7(30.4 \%)$ & \\
\hline Number of delayed ICU admissions, $N(\%)$ & $2(8.7 \%)$ & & $5(21.7 \%)$ & & $1(4.3 \%)$ & & $0(0.0 \%)$ & \\
\hline Number of late ICU admissions, $N(\%)$ & $5(21.7 \%)$ & & $1(4.3 \%)$ & & $1(4.3 \%)$ & & $1(4.3 \%)$ & \\
\hline Infection-related 28-day mortality, N (\%) & $0(0.0 \%)$ & & $10(13.5 \%)$ & & $6(6.0 \%)$ & & $14(16.5 \%)$ & \\
\hline Hospital mortality, N (\%) & $1(0.2 \%)$ & & $10(13.5 \%)$ & & $9(9.0 \%)$ & & $15(17.6 \%)$ & \\
\hline Disease progression, $N(\%)$ & $21(4.9 \%)$ & & $22(29.7 \%)$ & & $12(12.0 \%)$ & & $24(28.2 \%)$ & \\
\hline
\end{tabular}

Number of immediate, delayed, or late ICU admissions are expressed as a percentage of the total number of ICU admissions. ICU intensive care unit, i.v. intravenous, MR-proADM mid-regional proadrenomedullin, $N$ number, NEWS National Early Warning Score

Secondly, the rapid triage of high severity patients onto the ICU is mandatory in order to prevent further disease progression and maximise the chances of a successful treatment. Nevertheless, many patients are inappropriately triaged following ED presentation back into the community or onto a medical ward before any subsequent ICU admission, thus increasing the likelihood of a prolonged hospitalisation or ultimate mortality [8, 46, 47]. Our results suggest that the presence of low severity vital and physiological signs of infection may create a false impression concerning the requirement for immediate ICU admission, whilst elevated MR-proADM concentrations indicative of the early stages of developing organ dysfunction - may provide significant additional information in order to optimise decision-making. Similar findings have also previously been reported to predict renal replacement therapy (RRT) requirement in patients where no RRT was previously initiated [20] and in patients who progressed towards multiple organ failure $[15,16]$.

Finally, the results of this study suggest that MRproADM can accurately identify specific patient subgroups based on the likelihood of further clinical deterioration, thus helping to optimise subsequent treatment and triage decision-making. Results confirm those of a previous investigation [4], whilst further patient evaluation at $72 \mathrm{~h}$ found that MR-proADM was the only parameter to significantly decrease in surviving patients with low clinical scores, whilst tending to increase in non-survivors. Similar results have been found in previous investigations where continuously high or increasing MR-proADM concentrations in the ED [48] or ICU [15] were indicative of a subsequent detrimental outcome, or the requirement for an urgent clinical intervention.

We note several limitations and strengths of this study that deserve greater discussion. Firstly, a significant number of non-surviving patients showed no clinical deterioration at $72 \mathrm{~h}$ according to the calculation of clinical score values. Consecutive measurements should therefore be made across further time points to fully capture any subsequent deterioration. Nevertheless, such a finding is likely to be of relative clinical interest, since continuously elevated or increasing MR-proADM concentrations between both time points may potentially provide an earlier warning of treatment failure than conventional clinical scores. Secondly, numerous factors such as ED waiting times and physician availability may influence the timing of initial antibiotic administration [17], thus contributing to the differential analysis between clinical score and biomarker subgroups within this study. Future studies should therefore account for these variables in order to provide a more 
Table 4 NEWS and MR-proADM values upon ED presentation and $72 \mathrm{~h}$ within patient subgroups

\begin{tabular}{|c|c|c|c|c|c|c|c|c|}
\hline \multirow[t]{3}{*}{ Patient subgroups } & \multicolumn{8}{|c|}{ Patient populations stratified by NEWS and MR-proADM } \\
\hline & $\begin{array}{l}\text { MR-proADM } \\
\text { (nmol/L) }\end{array}$ & $\begin{array}{l}\text { NEWS } \\
\text { (points) }\end{array}$ & $\begin{array}{l}\text { MR-proADM } \\
\text { (nmol/L) }\end{array}$ & $\begin{array}{l}\text { NEWS } \\
\text { (points) }\end{array}$ & $\begin{array}{l}\text { MR-proADM } \\
\text { (nmol/L) }\end{array}$ & $\begin{array}{l}\text { NEWS } \\
\text { (points) }\end{array}$ & $\begin{array}{l}\text { MR-proADM } \\
\text { (nmol/L) }\end{array}$ & $\begin{array}{l}\text { NEWS } \\
\text { (points) }\end{array}$ \\
\hline & $<1.77$ & $<5$ & $\geq 1.77$ & $<5$ & $<1.77$ & $\geq 5$ & $\geq 1.77$ & $\geq 5$ \\
\hline Population, $N(\%)$ & $425(62.1 \%)$ & & $74(10.8 \%)$ & & $100(14.6 \%)$ & & $85(12.8 \%)$ & \\
\hline $\begin{array}{l}\text { Infection related 28-day mor- } \\
\text { tality, } N(\%)\end{array}$ & $0(0.0 \%)$ & & $10(13.5 \%)$ & & $6(6.0 \%)$ & & $14(16.5 \%)$ & \\
\hline \multicolumn{9}{|l|}{ NEWS: surviving patients } \\
\hline ED admission (points) & $1.72(1.29)$ & & $2.18(1.39)$ & & $7.18(1.71)$ & & $7.97(2.62)$ & \\
\hline $72 \mathrm{~h}$ (points) & $1.54(1.62)$ & & $2.08(2.26)$ & & $4.57(3.22)$ & & $3.61(2.48)$ & \\
\hline$p$ value & 0.182 & & 0.784 & & $<0.001$ & & $<0.001$ & \\
\hline \multicolumn{9}{|l|}{ NEWS: non-surviving patients } \\
\hline ED admission (points) & NA & & $2.60(0.97)$ & & $6.20(1.10)$ & & $8.36(2.69)$ & \\
\hline $72 \mathrm{~h}$ (points) & NA & & $2.63(2.07)$ & & $4.20(2.03)$ & & $4.90(3.31)$ & \\
\hline$p$ value & NA & & 0.875 & & $<0.05$ & & $<0.05$ & \\
\hline \multicolumn{9}{|l|}{ MR-proADM: surviving patients } \\
\hline ED admission (nmol/L) & $0.88(0.36)$ & & $2.78(1.16)$ & & $1.23(0.34)$ & & $3.39(1.47)$ & \\
\hline $72 \mathrm{~h}(\mathrm{nmol} / \mathrm{L})$ & $0.91(0.58)$ & & $1.80(1.11)$ & & $1.08(0.50)$ & & $2.13(1.36)$ & \\
\hline$p$ value & 0.56 & & $<0.001$ & & $<0.01$ & & $<0.001$ & \\
\hline \multicolumn{9}{|c|}{ MR-proADM: non-surviving patients } \\
\hline ED admission (nmol/L) & NA & & $3.22(1.37)$ & & $1.30(0.29)$ & & $2.77(1.38)$ & \\
\hline $72 \mathrm{~h}(\mathrm{nmol} / \mathrm{L})$ & NA & & $3.95(1.02)$ & & $1.41(0.35)$ & & $3.69(2.49)$ & \\
\hline$p$ value & NA & & 0.085 & & 0.548 & & 0.148 & \\
\hline
\end{tabular}

All NEWS and MR-proADM values are expressed as mean (standard deviation). MR-proADM mid-regional proadrenomedullin, $N$ number, NEWS National Early Warning Score

detailed calculation of time to administration. Thirdly, based on previous publications investigating the clinical utility of MR-proADM, additional secondary outcomes such as respiratory failure [49], acute kidney injury progression [50], and coronary ischaemia $[25,51]$ should be collected in order to further enhance our understanding of this novel biomarker due to its likely physiological action in endothelial injury and capillary leak. Finally, the relatively small number of patients in each subgroup, as well as low corresponding mortality and delayed ICU admission rates, allows for only initial hypotheses to be made and makes more detailed conclusions problematic. In addition, the presence of an independent validatory cohort, similar to that of Saeed et al. [4], utilising pre-specified and optimised cut-off values, would confer a greater degree of certainty to the obtained results.

\section{Conclusions}

The use of MR-proADM upon ED presentation may aid in the identification of patients with low NEWS or qSOFA values at risk of a less intensive treatment and with a subsequently high likelihood of further disease progression, thus helping guide initial treatment decisions such as antibiotic administration and ICU admission as part of a multi-modal clinical assessment. An additional measurement at $72 \mathrm{~h}$ may facilitate the identification of patients with continuously low NEWS scores at risk of treatment failure and subsequent mortality. Nevertheless, these results should be confirmed in an interventional study setting before subsequent incorporation into clinical routine.

\section{Supplementary information}

Supplementary information accompanies this paper at https://doi.org/10. 1186/s13054-019-2613-4.

Additional file 1: Table S1. Initial clinical diagnoses and suspected infectious source. Table $\mathbf{S 2}$. Characteristics of patients hospitalised at 72 h. Table S3. Univariate Logistic regression for antibiotic administration (ED treatment). Table S4. Univariate Logistic regression for hospitalisation requirement (ED presentation). Table S5. Univariate Logistic regression for ICU admission prediction (ED presentation). Table S6 Univariate Cox regression for the prediction of 28-day mortality (ED presentation). Table S7. Univariate Cox regression for the prediction of 28-day mortality (72 h). Table S8. Treatment and outcome in patients with low biomarker or score values (ED presentation). Table S9. Treatment and outcome in patients with high biomarker or score values (ED presentation). Table S10. Treatment and outcome in patients with low biomarker or score values (72 h). Table S11. Treatment and outcome in patients with high biomarker or score values (72 h). Table S12. Low NEWS patient subgroups classified according to Lactate and PCT kinetics between ED presentation and $72 \mathrm{~h}$. Table S13. Patient subgroups stratified by lactate and MRproADM. Table S14. Patient subgroups stratified by qSOFA and MR- 
proADM. Table S15. qSOFA and MR-proADM values upon presentation and $72 \mathrm{~h}$ within stratified subgroups. Table S16. Patient subgroups stratified by CRB-65 and MR-proADM. Table S17. Patient subgroups based on antibiotic administration using NEWS and MR-proADM. Table S18. Patient subgroups based on antibiotic administration using qSOFA and MRproADM. Figure S1. AUROC analysis for antibiotic requirement during treatment within the ED. Figure S2. AUROC analysis for hospitalisation requirement upon ED presentation. Figure S3. AUROC analysis for ICU admission within 28 days of initial ED presentation. Figure S4. AUROC analysis for infection-related 28-day mortality upon ED presentation and $72 \mathrm{~h}$.

\section{Abbreviations}

AUC: Area under the curve: CAP: Community-acquired pneumonia; Cl: Confidence interval; CRB-65: Severity scores for community-acquired pneumonia; CRP: C-reactive protein; ED: Emergency department; HR: Hazard ratio; IQR: Interquartile range; LRTI: Lower respiratory tract infection; MRproADM: Mid-regional proadrenomedullin; N: Number; NEWS: National Early Warning Score; OR: Odds ratio; PCT: Procalcitonin; PSI: Pneumonia severity index; qSOFA: Quick Sequential Organ Failure Assessment; ROC: Receiver operating characteristic; RRT: Renal replacement therapy; SIRS: Systemic inflammatory response syndrome; SOFA: Sequential Organ Failure Assessment; UTI: Urinary tract infection

\section{Acknowledgements}

The authors are grateful to the staff at all participating hospitals for their continued vigilance in identifying patients presenting with infections and for enrolling patients into this study. DCW would like to acknowledge the contributions made by Monika Wittmann concerning graphical presentation. Addendum collaborators

Members of the Infectious Disease Group of the Spanish Emergency Medicine Society (INFURG-SEMES) participating in this study: Joan Ramon Pérez-Mas, Elena Fuentes-González, and Concepción Martínez-Muñoz (Emergency Department, Hospital Universitari de Bellvitge, Barcelona, Spain); Elena Martínez-Beloqui (Emergency Department, Short Stay Unit and Home Hospitalization Unit, Hospital General de Alicante, Alicante, Spain); and Francisco Javier Martín-Sánchez, Paula Mostaza Gallar, Luis Picazo García, and Alejandro Malo de Molina Herrera (Emergency Department, Hospital Clínico San Carlos, Madrid, Spain).

\section{Authors' contributions}

JGC and DCW conceived and designed the study. JGC was the primary author, the editor of the manuscript, and the lead clinical investigator. All authors apart from DCW contributed to the enrolment of patients and sample collection. JGC and DCW provided statistical advice and analysed the data. All authors critically reviewed and approved the final manuscript. JGC takes responsibility for the paper as a whole.

\section{Funding}

The study was funded by a restricted grant from Thermo Fisher (Germany). However, the funding organisation had no role in the collection, management, analysis, or interpretation of the data; preparation, review, or approval of the manuscript; or decision to submit the manuscript for publication.

\section{Availability of data and materials}

The datasets used and/or analysed during the present study are available from the corresponding author upon reasonable request.

\section{Ethics approval and consent to participate}

The study protocol was approved by the ethics board of each hospital where necessary, and written informed consent was obtained from all patients or their legal representatives where appropriate.

\section{Consent for publication}

No individual participant data is reported that would require consent to publish from the participant (or legal parent or guardian for children).

\section{Competing interests}

The authors declare that they have no competing interests.

\section{Author details}

${ }^{1}$ Emergency Department, Hospital Clínico San Carlos, Madrid, Spain. ${ }^{2}$ San Carlos Clinical Research Institute Hospital San Carlos (IdISSC), Madrid, Spain. ${ }^{3}$ Shock, Organ Dysfunction and Resuscitation Research Group, Vall d'Hebron Institute of Research, Barcelona, Spain. ${ }^{4}$ Emergency Department, Short Stay Unit and Home Hospitalization Unit, Hospital General de Alicante, Alicante, Spain. ${ }^{5}$ Emergency Department, Hospital Universitari de Bellvitge, Barcelona, Spain. ${ }^{6}$ Internal Medicine Department, Hospital Clínico San Carlos, Madrid, Spain. ${ }^{7}$ Clinical Laboratory Department, Hospital Universitari de Bellvitge, Barcelona, Spain.

Received: 11 April 2019 Accepted: 13 September 2019

Published online: 29 October 2019

\section{References}

1. Chen $\mathrm{H}-\mathrm{C}$, Lin W-L, Lin C-C, Hsieh W-H, Hsieh C-H, Wu M-H, et al. Outcome of inadequate empirical antibiotic therapy in emergency department patients with community-onset bloodstream infections. J Antimicrob Chemother. 2012;68(4):947-53.

2. Chalfin DB, Trzeciak S, Likourezos A, Baumann BM, Dellinger RP. Impact of delayed transfer of critically ill patients from the emergency department to the intensive care unit*. Crit Care Med. 2007:35(6):1477-83.

3. Gaieski DF, Mikkelsen ME, Band RA, Pines JM, Massone R, Furia FF, et al. Impact of time to antibiotics on survival in patients with severe sepsis or septic shock in whom early goal-directed therapy was initiated in the emergency department*. Crit Care Med. 2010;38(4):1045-53.

4. Saeed K, Wilson DC, Bloos F, Schuetz P, van der Does Y, Melander O, et al. The early identification of disease progression in patients with suspected infection presenting to the emergency department: a multi-centre derivation and validation study. Crit Care. 2019;23(1):40.

5. Stalenhoef JE, Nieuwkoop C, Wilson DC, Starre WE, Delfos NM, Leyten EMS, et al. Biomarker guided traige can reduce hospitalisation rate in community acquired febrile urinary tract infection. J Infect. 2018;77(1):18-24.

6. van der Does Y, Limper M, Jie KE, Schuit SCE, Jansen H, Pernot N, et al. Procalcitonin-guided antibiotic therapy in patients with fever in a general emergency department population: a multicentre non-inferiority randomized clinical trial (HiTEMP study). Clin Microbiol Infect. 2018;24(12):1282-9.

7. Seymour CW, Gesten F, Prescott HC, Friedrich ME, Iwashyna TJ, Phillips GS, et al. Time to treatment and mortality during mandated emergency care for sepsis. N Engl J Med. 2017;376(23):2235-44.

8. Fernando SM, Rochwerg B, Reardon PM, Thavorn K, Seely AJE, Perry JJ, et al. Emergency department disposition decisions and associated mortality and costs in ICU patients with suspected infection. Crit Care. 2018;22(1):172.

9. Morr M, Lukasz A, Rubig E, Pavenstadt H, Kumpers P. Sepsis recognition in the emergency department - impact on quality of care and outcome? BMC Emerg Med. 2017;17(1):11.

10. Peterson LN, Chase K. Pitfalls in the treatment of sepsis. Emerg Med Clin North Am. 2017;35(1):185-98

11. Glickman SW, Cairns CB, Otero RM, Woods CW, Tsalik EL, Langley RJ, et al. Disease progression in hemodynamically stable patients presenting to the emergency department with sepsis. Acad Emerg Med. 2010;17(4):383-90.

12. Holder AL, Gupta N, Lulaj E, Furgiuele M, Hidalgo I, Jones MP, et al. Predictors of early progression to severe sepsis or shock among emergency department patients with nonsevere sepsis. Int J Emerg Med. 2016;9(1):10.

13. Capp R, Horton CL, Takhar SS, Ginde AA, Peak DA, Zane R, et al. Predictors of patients who present to the emergency department with sepsis and progress to septic shock between 4 and 48 hours of emergency department arrival. Crit Care Med. 2015;43(5):983-8.

14. Graziadio S, O'Leary RA, Stocken DD, Power M, Allen AJ, Simpson AJ, et al. Can mid-regional pro-adrenomedullin (MR-proADM) increase the prognostic accuracy of NEWS in predicting deterioration in patients admitted to hospital with mild to moderately severe illness? A prospective single-centre observational study. BMJ Open. 2019:8(11):e020337.

15. Elke G, Bloos F, Wilson DC, Brunkhorst FM, Briegel J, Reinhart K, et al. The use of mid-regional proadrenomedullin to identify disease severity and treatment response to sepsis - a secondary analysis of a large randomised controlled trial. Crit Care. 2018;22(1):79.

16. Elke G, Bloos F, Wilson DC, Meybohm P. Identification of developing multiple organ failure in sepsis patients with low or moderate SOFA scores. Crit Care. 2018;22(1):147. 
17. Dellinger RP, Levy MM, Rhodes A, Annane D, Gerlach H, Opal SM, et al. Surviving sepsis campaign: international guidelines for management of severe sepsis and septic shock: 2012. Crit Care Med. 2013;41(2):580-637.

18. Freund $Y$, Khoury A, Möckel M, Karamercan M, Dodt C, Leach R, et al. European Society of Emergency Medicine position paper on the 1-hour sepsis bundle of the Surviving Sepsis Campaign: expression of concern. Eur J Emerg Med. 2019;26(4):232-3

19. Viaggi B, Poole D, Tujjar O, Marchiani S, Ognibene A, Finazzi S. Mid regional pro-adrenomedullin for the prediction of organ failure in infection. Results from a single centre study. PLoS One. 2018;13(8):e0201491.

20. Nierhaus A, Bloos F, Wilson DC, Elke G, Meybohm P, SepNet Critical Care Trials G. Predicting the requirement for renal replacement therapy in intensive care patients with sepsis. Crit Care. 2018;22(1):201.

21. Angus DC, van der Poll T. Severe sepsis and septic shock. N Engl J Med. 2013;369(21):2063.

22. Temmesfeld-Wollbruck B, Hocke AC, Suttorp N, Hippenstiel S. Adrenomedullin and endothelial barrier function. Thromb Haemost. 2007;98(5):944-51.

23. Pittard AJ, Hawkins WJ, Webster NR. The role of the microcirculation in the multi-organ dysfunction syndrome. Clin Intensive Care. 1994;5(4):186-90.

24. Vigue B, Leblanc PE, Moati F, Pussard E, Foufa H, Rodrigues A, et al. Midregional pro-adrenomedullin (MR-proADM), a marker of positive fluid balance in critically ill patients: results of the ENVOL study. Crit Care. 2016;20(1):363.

25. Adlbrecht C, Hulsmann M, Strunk G, Berger R, Mortl D, Struck J, et a Prognostic value of plasma midregional pro-adrenomedullin and Cterminal-pro-endothelin-1 in chronic heart failure outpatients. Eur J Heart Fail. 2009;11(4):361-6.

26. Maisel A, Mueller C, Nowak RM, Peacock WF, Ponikowski P, Mockel M, et al. Midregion prohormone adrenomedullin and prognosis in patients presenting with acute dyspnea: results from the BACH (Biomarkers in Acute Heart Failure) trial. J Am Coll Cardiol. 2011;58(10):1057-67.

27. Nickel CH, Messmer AS, Geigy N, Misch F, Mueller B, Dusemund F, et al. Stress markers predict mortality in patients with nonspecific complaints presenting to the emergency department and may be a useful risk stratification tool to support disposition planning. Acad Emerg Med. 2013;20(7):670-9.

28. Xie Z, Chen WS, Yin Y, Chan EC, Terai K, Long LM. Adrenomedullin surges are linked to acute episodes of the systemic capillary leak syndrome (Clarkson disease). J Leukoc Biol. 2018;103.

29. Courtais C, Kuster N, Dupuy AM, Folschveiller M, Jreige R, Bargnoux AS, et al. Proadrenomedullin, a useful tool for risk stratification in high Pneumonia Severity Index score community acquired pneumonia. Am J Emerg Med. 2013;31(1):215-21.

30. Huang DT, Angus DC, Kellum JA, Pugh NA, Weissfeld LA, Struck J, et al. Midregional proadrenomedullin as a prognostic tool in communityacquired pneumonia. Chest. 2009;136(3):823-31.

31. Espana PP, Capelastegui A, Mar C, Bilbao A, Quintana JM, Diez R, et al. Performance of pro-adrenomedullin for identifying adverse outcomes in community-acquired pneumonia. J Inf Secur. 2015;70(5):457-66.

32. Julian-Jimenez A, Yanez MC, Gonzalez-Del Castillo J, Salido-Mota M, MoraOrdonez B, Arranz-Nieto MJ, et al. Prognostic power of biomarkers for shortterm mortality in the elderly patients seen in emergency departments due to infections. Enferm Infecc Microbiol Clin. 2019;37(1):11-18.

33. Cavallazzi R, El-Kersh K, Abu-Atherah E, Singh S, Loke YK, Wiemken T, et al. Midregional proadrenomedullin for prognosis in community-acquired pneumonia: a systematic review. Respir Med. 2014;108(11):1569-80.

34. Renaud B, Schuetz P, Claessens YE, Labarere J, Albrich W, Mueller B. Proadrenomedullin improves risk of early admission to ICU score for predicting early severe community-acquired pneumonia. Chest. 2012;142(6):1447-54.

35. Spellberg B, Bartlett J, Wunderink R, Gilbert DN. Novel approaches are needed to develop tomorrow's antibacterial therapies. Am J Respir Crit Care Med. 2015;191(2):135-40

36. Huijskens EG, Koopmans M, Palmen FM, van Erkel AJ, Mulder PG, Rossen JW. The value of signs and symptoms in differentiating between bacterial, viral and mixed aetiology in patients with community-acquired pneumonia. J Med Microbiol. 2014;63(Pt 3):441-52.

37. Ferrer R, Martin-Loeches I, Phillips G, Osborn TM, Townsend S, Dellinger RP, et al. Empiric antibiotic treatment reduces mortality in severe sepsis and septic shock from the first hour: results from a guideline-based performance improvement program. Crit Care Med. 2014:42(8):1749-55.

38. Laxminarayan R, Duse A, Wattal C, Zaidi AK, Wertheim HF, Sumpradit N, et al. Antibiotic resistance-the need for global solutions. Lancet Infect Dis. 2013;13(12):1057-98
39. Rosenqvist M, Wilson DC, Tegnér L, Bengtsson-Toni M, Peyman M, del Castillo $J \mathrm{G}$, et al. Biomarkers to guide antibiotic timing and administration in infected patients presenting to the emergency department. Crit Care. 2019;23(1):141.

40. Gille J, Ostermann H, Dragu A, Sablotzki A. MR-proADM: a new biomarker for early diagnosis of sepsis in burned patients. J Burn Care Res. 2017;38(5):290-8.

41. de Kruif MD, Lemaire LC, Giebelen IA, Struck J, Morgenthaler NG, Papassotiriou $J$, et al. The influence of corticosteroids on the release of novel biomarkers in human endotoxemia. Intensive Care Med. 2008;34(3):518-22.

42. Decker SO, Sigl A, Grumaz C. Immune-response patterns and next generation sequencing diagnostics for the detection of mycoses in patients with septic shock - results of a combined clinical and experimental investigation. Int J Mol Sci. 2017;18(8).

43. Angeletti S, Battistoni F, Fioravanti M, Bernardini S, Dicuonzo G. Procalcitonin and mid-regional pro-adrenomedullin test combination in sepsis diagnosis. Clin Chem Lab Med. 2013;51(5):1059-67.

44. Angeletti S, Spoto S, Fogolari M, Cortigiani M, Fioravanti M, De Florio L, et al. Diagnostic and prognostic role of procalcitonin (PCT) and MR-proadrenomedullin (MR-proADM) in bacterial infections. APMIS. 2015;123(9):740-8.

45. Spoto S, Cella E, de Cesaris M, Locorriere L, Mazzaroppi S, Nobile E, et al. Procalcitonin and Mr-proadrenomedullin combination with SOFA and qSOFA scores for sepsis diagnosis and prognosis: a diagnostic algorithm. Shock. 2018; 50(1):44-52.

46. Hung SC, Kung CT, Hung CW, Liu BM, Liu JW, Chew G, et al. Determining delayed admission to intensive care unit for mechanically ventilated patients in the emergency department. Crit Care. 2014;18(4):485.

47. Phua J, Ngerng WJ, Lim TK. The impact of a delay in intensive care unit admission for community-acquired pneumonia. Eur Respir J. 2010;36(4):826-33.

48. Hartmann O, Schuetz P, Albrich WC, Anker SD, Mueller B, Schmidt T. Timedependent Cox regression: serial measurement of the cardiovascular biomarker proadrenomedullin improves survival prediction in patients with lower respiratory tract infection. Int J Cardiol. 2012;161(3):166-73.

49. Bello S, Lasierra AB, Minchole E, Fandos S, Ruiz MA, Vera E, et al. Prognostic power of proadrenomedullin in community-acquired pneumonia is independent of aetiology. Eur Respir J. 2012;39(5):1144-55.

50. Dieplinger B, Mueller T, Kollerits B, Struck J, Ritz E, von Eckardstein A, et al. Pro-A-type natriuretic peptide and pro-adrenomedullin predict progression of chronic kidney disease: the MMKD study. Kidney Int. 2009;75(4):408-14.

51. von Haehling S, Filippatos GS, Papassotiriou J, Cicoira M, Jankowska EA, Doehner W, et al. Mid-regional pro-adrenomedullin as a novel predictor of mortality in patients with chronic heart failure. Eur J Heart Fail. 2010;12(5):484-91.

\section{Publisher's Note}

Springer Nature remains neutral with regard to jurisdictional claims in published maps and institutional affiliations.

\section{Ready to submit your research? Choose BMC and benefit from:}

- fast, convenient online submission

- thorough peer review by experienced researchers in your field

- rapid publication on acceptance

- support for research data, including large and complex data types

- gold Open Access which fosters wider collaboration and increased citations

- maximum visibility for your research: over $100 \mathrm{M}$ website views per year

At BMC, research is always in progress.

Learn more biomedcentral.com/submission 